\title{
Latino Students in New Arrival States: Factors and Services to Prevent Youth From Dropping Out
}

By: Andrew O. Behnke, Laura M. Gonzalez and Ronald B. Cox

Behnke, A. O., Gonzalez, L. M., \& Cox, R. B. (August 01, 2010). Latino students in new arrival states: Factors and services to prevent youth from dropping out. Hispanic Journal of Behavioral Sciences, 32, 3, 385-409.

Made available courtesy of SAGE Journals:

http://hjb.sagepub.com/content/32/3/385.abstract?rss=1\&patientinform-

links=yes\&legid=sphjb;32/3/385

*** Reprinted with permission. No further reproduction is authorized without written permission from SAGE. This version of the document is not the version of record. Figures and/or pictures may be missing from this format of the document. ${ }^{* * *}$

\section{$\underline{\text { Abstract }}$}

Latino youth are more likely than any other ethnic group to drop out of high school in the United States. Though some research has helped us understand the factors leading to dropout, very few studies have assessed Latino student's opinions of services and factors that would help them stay in school (e.g., family, school, peers, and policies). This study presents the results of an in-depth survey of 501 Latino students in North Carolina public schools. Findings suggest that Latino youth drop out because of the difficulty of their school work, personal problems (e.g., pregnancy or problems at home), the need to work to support their family economically, and peer pressure. Students suggest improved academic and personal support in the form of tutoring, mentoring, after-school programs; improved English as a second language classes; and more Spanishspeaking staff/teachers. Recommendations for intervention and policy are suggested.

\section{$\underline{\text { Keywords }}$}

Latino, dropout, high school, academic, prevention

\section{New Arrival Communities}

An important demographic change in the United States in recent years has been the dramatic growth in the numbers of Latinos migrating to new arrival communities, such as Georgia, North Carolina, and Arkansas (Capps, Fix, Ost, Reardon-Anderson, \& Passel, 2004; Dinan, 2005; Marotta \& Garcia, 2003). There are important differences between states where Latinos have traditionally settled and lived for generations (e.g., California, Florida, New York, Texas) and some of the states where immigration has occurred more recently (North Carolina, South Carolina, Georgia, Tennessee, Arkansas, Alabama, and Nevada; Pew Hispanic Center, 2004). 
The majority of these immigrants come from Mexico and have great economic necessity, limited formal education, limited use of English, and tend to accept low wage positions in the United States (Capps, 2009). In many cases, these difficulties are aggravated by the fact that many of these families arrive in new receiving communities that are financially, socially, and structurally unprepared to meet their needs (Stamps \& Bohon, 2006). The case of North Carolina will be used as an example of the transitions and challenges being seen in many new arrival areas.

Between 1990 and 2007, there was nearly a 10-fold increase in North Carolina's Latino population, which grew from 69,020 to 643,333 (U.S. Census Bureau, 2008), the largest growth over that period in the entire United States. Recent data from births in North Carolina project another 10-fold increase among the Latino high school student population from the current number of about 4,483 in 2008 to more than 57,000 in the year 2020 (Western Interstate Commission for Higher Education, 2003). These increases in North Carolina's Latino high school population coincide with high rates of high school dropout. Research shows that only 56\% of Latino youth in North Carolina graduated from high school in 4 years in 2008 (North Carolina Department of Public Instruction, 2009).

\section{Reasons for Latino Youth Dropout}

On the national level, many of the reasons for Latino dropout are correlated with socioeconomic status; indeed, when socioeconomic status is controlled for among racial and ethnic groups, the dropout rates become quite similar (Schmid, 2001). Still, despite many studies reporting on factors associated with not finishing school, much is unknown. One study of approximately 9,000 North Carolina 9th graders showed that the most frequently provided reason for Latinos to drop out was "unknown," or in other words, there was insufficient data to indicate why they had dropped out (Glennie \& Stearns, 2002). Moreover, the North Carolina Department of Public Instruction uses "attendance" as a general category for dropout when no other codes are applicable, and this usually accounts for approximately $50 \%$ of the total rate. Though reasons Latinos drop out of school has not previously been well documented, in the subsequent sections we describe some of the more common

factors.

Individual youth factors. Four individual youth-related factors are often cited in recent research: supporting one's family economically by working, having difficulty completing school work, experiencing personal problems (pregnancy or stressors at home), and peer pressure (Perreira, Harris, \& Lee, 2006). First, among the most commonly reported reasons for Latino dropout has consistently been the desire to get a job (Bridgeland, Dilulio, \& Burke Morison, 2004; Glennie \& Stearns, 2002; Perreira et al., 2006). For example, Perriera et al. (2006) found that early employment dissuaded more youth to drop out of school than any other factor they studied (such as generational poverty, teen pregnancy, delinquency, or limited higher education opportunities). The importance of contributing to one's family (whether economically or in other ways) is 
central to collective cultural traditions and may thus cause value conflicts with individual activities such as schooling (Constantine, Kindaichi, \& Miville, 2007; Dagenais, Montmarquette, \& Viennot-Briot, 2007). However, in a recent report on youth in Oklahoma, early employment among youth was related to a sense of ambivalence toward the future because

of not having the proper documents to find meaningful employment past high school (Cox, Shreffler, Schwerdtfeger, \& Merten, 2010). Youth in this study related that with or without a high school diploma they were destined to a life of manual labor, making the choice of early employment more attractive then finishing high school. In fact, one study found that Latinos who do not see the benefit of completing a high school education (e.g., those that do not have access to postsecondary education because of their legal status) may become both "academically and socially disengaged from school” (Constantine et al., 2007, p. 262).

Second, immigrant Latino youth commonly report that they struggle to complete homework and school assignments. The mobility associated with recent immigration and limited English proficiency make it difficult for Latino students to achieve in their classes and leads many to drop out (Glennie \& Stearns, 2002; Perreira et al., 2006; Rumberger, 1995). These youth may become proficient in spoken English in a short period of time; however, many youth struggle with written and academic English usage (Hess, 2000). As such academic progress is much more difficult when studying and being tested in a second language. Schools in North Carolina and other new arrival communities vary in the amount and type of support provided to English as a second language (ESL) students to help them overcome these language related difficulties. Still, the research is not entirely clear on this point. At least one study of youth from North Carolina found that Latinos were less likely than the rest of the sample to cite academic or disciplinary reasons for leaving school (Glennie \& Stearns, 2002). There is no doubt that academically disadvantaged students can still succeed; however, it requires the combination of time on task and caring adults who help the youths develop motivation, pride in their work, and efficacy for academic tasks (Aspiazu, Bauer, \& Spillett, 1998).

Third, personal problems are not limited to Latino students, but social difficulties may be intensified for immigrant youth. Among some of the most common issues, Latino youth rank highest in recent reports of teen depression, suicidal thoughts, sexual risk taking, and teen pregnancy (Eaton et al., 2008). For example, in recent years teen pregnancy has been shown to be higher among Latinas than any other ethnic group (Hamilton, Martin, \& Ventura, 2007; Ventura, Abma, Mosher, \& Henshaw, 2007). Although many schools endeavor to provide language-related services for such students, the presence of a Spanish-speaking or culturally literate counselor is less common (Smith-Adcock, Daniels, Lee, Villalba, \& Indelicato, 2006). Counselors can help address academic, personal, career, and social issues and thus diminish students' feelings of isolation or cultural conflict. Counselors could also serve as a bridge between the school and home environment, finding resources for students whose problems outside of school are affecting their ability to persist and progress. 
Fourth, as with all youth, negative peer affiliations play a significant role in the behaviors and decision making of Latino youth (Wall, Power, \& Arbona, 1993). In general, research shows that youth with friends who have dropped out of school are much more likely to drop out themselves (Ellenbogen \& Chamberland, 1997; Rumberger \& Thomas, 2000). This is shown to be the case for Latino youth as well. Latino youth with friends who have left school are much less likely to experience academic success and complete high school (Hess, 2000; Velez \& Saenz, 2001). Other research has shown that male youth are more susceptible to the negative influences of their peers than their female peers (Bámaca \& Umaña-Taylor, 2006; Wall et al., 1993). Considering these previous studies, we would expect Latino youth in this study to report that peer pressure or negative peer relationships are a major factor in their peers' dropout intentions.

Family factors. Ecological theory suggests that individual behaviors are influenced by several rings of social structure, including family, school, community, and culture (Bronfenbrenner, 1979). Dropout may also be examined through this lens, expanding the traditional focus on individual factors to include family, school, peers, local communities, states and national policies, and the interactions among those entities (Hess, 2000). Some of the family factors that are reported to influence Latino student drop out are family structure (single- or dual-parent households), parenting style (permissiveness), family economic status, parental level of human capital (education, training, work type, and experience), quality of neighborhood where the family resides, frequent moves or changes of school, and amount and quality of contact between parents and school (Lopez \& Sanchez, 2000; Velez \& Saenz, 2001).

Research has pointed to the salient influence of parents on the academic success of Latino youth (e.g., Delgado-Gaitan, 1992, 1994; Plunkett \& Bámaca-Gómez, 2003). Studies suggest that two factors essential to improving academic success and dropout prevention are parental involvement (Gonzalez-DeHass, Willems, \& Holbein, 2005) and parental academic motivation (Alfaro, Umaña-Taylor, \& Bámaca, 2006). In fact, one recent study found parent involvement was the single strongest predictor of Latino academic success (Zuniga, 2004). Parental involvement has been positively related to Latinos’ academic achievement, by means of parents' high academic standards and expressed commitment to the benefits of education (Ceballo, 2004; Gándara, Larson, Mehan, \& Rumberger, 1998). Ramirez (2003) demonstrated that immigrant parents desired to be a part of their children's education but felt that schools did not listen to their needs. Latino parents on average have less experience in navigating the U.S. educational system and may be more reluctant to be involved in school environments as compared with the U.S.-born Latino, Caucasian, and African American parents (Pew Hispanic Center/Kaiser Family Foundation, 2004). School-family-community collaborations can be effective in improving school completion for Latinos, especially if a school counselor is able to form and maintain an effective partnership among the key parties (Dotson-Blake, Foster, \& Gressard, 2009).

Family mobility among Latinos is also a predictor of dropout. Latino families are more likely to move during their students schooling years (Rumberger, Larson, Ream, \& Palardy, 1999). Glennie and Stearn's (2002) study of youth from North Carolina compared Latino youth with all 
students in the sample and found that Latino students experienced more transience (6.4\% comparedwith $16 \%$ of Latinos stating that they had to move) and were almost twice as likely to cite family as their reason for dropping out (4.8\% vs. 8.4\%). Despite the increased risks noted earlier, many Latino families have been shown to work together to make academic success a reality (Ceballo, 2004).

School and structural factors. The environmental context of reception in new arrival states is critically important as structures may not be in place and individuals may be unaccustomed to interacting (Schmid, 2001). The relative isolation of new immigrant students (because of linguistic and cultural differences) means fewer opportunities for peers in the school to build a constructive social and educational environment (Dotson-Blake, Foster, \& Gressard, 2009), which leads to decreases in institutional bonding and related drop out (Katz, 1999).

Teachers may also be facing classroom dynamics that they were not prepared for, and their reactions could range from helpful to neutral to unhelpful. A recent unpublished doctoral dissertation discussed the importance of the school environment in the Latino dropout equation (Anderson, 2004). Anderson indicated that teachers and other school staff can exert an important influence when they hold high expectations for Latino students and communicate to students that they believe in their potentials. These culturally sensitive relationships were found to be key to preventing dropout in Anderson's analysis.

For school years 2001 to 2005, Latino students accounted for 57\% of total growth in North Carolina public schools (Kasarda \& Johnson, 2006). Many of these youth are native speakers of Spanish or another language, as demonstrated by the almost $400 \%$ increase in limited English proficiency students from 1994 to 2004 in North Carolina (Capps, 2009). Today, many schools in new arrival states lack sufficient support structure to accommodate the needs of Latino students, especially those with limited proficiency in English. Currently in North Carolina, 357 teachers are offering ESL courses in public schools to 9- to 12th-grade students (this designation excludes courses such as math taught to English language learners). There are 588 public secondary schools, some with several such ESL teachers and some with none; conservatively, $60 \%$ of the schools have designated ESL courses and teachers. Limited English proficiency learners are quite vulnerable to dropout, with a rate close to $30 \%$ by some estimates (Capps, 2009).

Other studies have demonstrated that a school's Latino dropout rate is related to a school's lowered expectations for Latino youth and limited cultural training (Falbo, 1996; Katz, 1999). Portes and MacLeod (1996) found that the structure of schools (few ESL teachers or bilingual staff, limited outreach to parents) had significant relationship with academic performance of Latino immigrant youth. Some ESL programs operate independently from the general school system and may generate a segregated structure for the students. School counselors and ESL instructors are the most likely advocates for new Latino immigrants but may not interact with each other or with regular classroom teachers enough to develop effective strategies or teamwork 
(Clemente \& Collison, 2000). Other structural factors that are related to Latino high school completion, which are often lacking in new arrival states, include lack of school documents translated into other languages, few live translators to help parents interact, and limited outreach and/or advocacy for these youth (e.g., Falbo, 1996).

Political and social climate influences. The current social climate in North Carolina is mirrored in the public schools. The contentious nature of the debate on immigration influences the perceptions of the students (of all backgrounds and cultural affiliations), teachers, administrators, and parents in the community (Stone \& Han, 2005). An ethnographic study of Latinos in Hope City, North Carolina, noted that

the most disastrous effects were at the high school level, where racism in the form of peer discrimination, institutional tracking, and inferior education for English language learners were rampant. Indeed the majority of Latino students were situated in the lowest tracks, and the unusually high dropout rate was under legal investigation. (Villenas, 2002, p. 20)

A qualitative study that interviewed parents of Latino elementary students in a rural southeastern community elaborated on four factors that affected the children (Villalba, Brunelli, Lewis, \& Orfanedes, 2007): (a) teacher or school characteristics (such as encouraging, respectful, collaborative, helpful), (b) academic experiences, (c) family/cultural traits, and (d) social factors (such as a small or transient Latino community, gang activity in school, hostility in the general community, and lack of support resources).

Undocumented students in the United States face challenges to accessing higher education in all but 10 states (Frum, 2007). Currently, North Carolina is one of only three states in the nation where undocumented immigrant youth are not permitted to attend community colleges in the state, although the policy is under review (Zota, 2009). Previous to this decision in 2007, youth were allowed access, albeit paying out of state tuition. Community colleges are the venue of choice for many Latino youth; however, this and other legal and political decisions made in the state have made it more difficult for youth to gain access to the professional or educational opportunities they desire (Frum, 2007; Muñoz, 2009). Indeed, many Latino youth and their parents believe that college is not an option for them (Frum, 2007; Lagerwey \& Phillips, 2003; Muñoz, 2009).

\section{Consequences of Dropout}

Individuals who drop out of high school may experience lowered aspirations, self-efficacy, and self-worth and are much more likely to live in poverty or experience other undesirable outcomes (e.g., substance abuse). Beyond the personal consequences to these students, the statewide economic impact of high school dropouts is staggering. In 2006, dropouts cost North Carolina 7.5 billion dollars in lost income, amounting to an 11 billion dollar annual negative impact on the state's economy (Gottlob, 2007). Substantial numbers of Latino youth in North Carolina will likely have decreased job prospects, heightened unemployment, and increased poverty in the 
future if dropout rates remain unchanged (Glennie \& Stearns, 2002; Martinez, DeGarmo, \& Eddy, 2004). Research has shown that youth who dropout of school are twice as likely to be unemployed, and for those who work, advancement is limited, the pay is low (the average high school dropout earns just 37 cents for every dollar earned by a high school graduate), and health insurance is not readily available (Rouse, 2005; Steinberg, Johnson, \& Pennington, 2006). These staggering statistics point to the need for a further understanding of why recently immigrated Latino youth in new arrival states are dropping out of school and what preventative measures might have an impact.

Little research has asked what youth think can be done to prevent their peers from dropping out. Lagerwey and Phillips (2003) have asked rural Latino youth what made it possible for them to stay in school, yet they did not explore directly what preventative measures could be taken to help at-risk youth stay in school. In order to gain a better understanding of what could be done to help Latino student stay in school, an in-depth descriptive approach was developed to investigate three applied research questions related to new arrival states (exemplified by North Carolina). First, what factors do Latino high school students in new arrival states such as North Carolina feel lead their Latino peers to dropout? Second, what services and factors do Latino youth feel will help prevent their peers from dropping out of school? Third, what policy and structural implications do these findings present to leaders in states similar to North Carolina?

\section{Method}

\section{Sample and Procedure}

In order to gain a clearer understanding of the issues that Latino youth are facing in North Carolina schools and to assess the reasons why youth feel their peers are dropping out, ESL teachers were sent a six-page survey to be completed by Latino students in their class. Approximately 36 teachers received the survey 2 weeks prior to the 2008 Hispanic Achievement Conference organized by the North Carolina Society of Hispanic Professionals because they had expressed interest in attending the event. Teachers were asked to have their students bring the surveys with them to the conference in exchange for the opportunity to win a computer.

Approximately 524 Latino 6th to 12th graders from 36 school districts returned surveys. Twentythree surveys were more than $50 \%$ incomplete and were discarded. Complete data were provided by 218 males and 283 females $(\mathrm{N}=501)$. In general, students came from homes where Spanish was the primary language (83\%) and where the participants described differences in the level of English fluency between the parent generation (approximately 60\% rated their parents’ English speaking ability as not at all or not very well) and the student generation (approximately 70\% rated their own English speaking ability as fully fluent or very well). The large majority of the sample was first-generation Latino students (90\%; with the majority of Mexican origin), and though there was variation in the number of years students had lived in the United States, half of the students reported that they had lived in the United States for less than 6 years. All survey responses were confidential; researchers accessed the de-identified data after they were collected 
by North Carolina Society of Hispanic Professionals. Institutional review board approval was granted to use the data on the basis of secondary analysis of an extant data set.

\section{Measures}

Three professional bilingual, native Spanish-speaking project staff translated the survey materials from English to Spanish. Participants on average took 30 minutes to complete the survey, and youth who completed the survey were given a chance to win a laptop. The questionnaire involved 50 closedended and 11 open-ended questions, which assessed for general demographics, parent engagement, peer support, teacher/staff support, factors leading to dropout, and factors preventing dropout. Though some of the sets of questions in the larger survey were used or adapted from published measurement tools, this study only uses seven questions that were created to address the current research questions. Our seven questions (described below) focus on students' perceived reasons for drop out and factors students believe will prevent dropout.

Reasons for dropping out. Three questions offered the youth opportunities to describe what they believed led their peers to drop out. One multiple select question asked, "What are the main reasons that you know of or believe to be the cause of students dropping out of school?” Students could select up to four of eight prescribed reasons that described why their peers were dropping out of school or could write in their own response. A second multiple select question asked, "What are the problems/dangers that you face at school, if any?” Again, participants could choose up to four reasons from eight answer choices that were provided or write in their own reason. A third open-ended question explored Latino youths' perceptions of factors that made it harder for their peers to graduate from school ("What makes it hard for your peers to stay in school?”).

Factors preventing dropout. Four questions (two open-ended and two multiple select) were used to assess the kinds of services and factors youth felt would help prevent their peers from dropping out of school. One item inquired about specific services ("What kind of services and/or classes would help prevent students from dropping out of school?”). A second more broadly

phrased question asked youth, "What do you think could be done to prevent youth from dropping out of school?” Third, youth were asked to use a 3-point Likert-type scale to address "How important would it be to have certain services/classes offered in order to prevent students from dropping out of school?" Finally, a multiple select question asked, "What kind of services and/or classes would you like to be offered in order to help you as a student?” Participants could choose up to three from five responses that were provided or could write in their own idea.

\section{Data Analyses}

The demographic and closed-ended survey question data were analyzed using simple descriptive statistics. The open-ended questions were analyzed using analytic induction and constant comparison methods, allowing patterns, themes, and categories to emerge from the data 
(LeCompte \& Priessle, 1993; Patton, 1990). To begin the data analysis process, the research team independently read the survey responses. Responses were grouped for each question by recurring concepts, and then the identified concepts were refined into initial categories. Once the categories were agreed on, team members independently reread the survey responses, noted recurring themes, and identified common elements. After team members independently coded the transcripts, they met to review coding and arrive at agreement about the coding of the data. In the few places where coding differed, we deliberated until a consensus was reached for each response. Frequencies of themes are reported in the following section because of the large number of responses.

\section{Results}

\section{What Are the Main Reasons That You Know of or Believe To Be the Cause of Students Dropping Out of School?}

In response to the multiple select questions about the main reasons that led their peers to drop out, $75 \%$ of the students checked "personal reasons (pregnancy, problems at home)" as one of the four possible choices for why their peers drop out of school. The second most commonly selected reason was that the peer had "academic struggles (bad grades)," at 54\%. The third most frequently reported reason (50\%) was "wanted to work." Other responses participants chose to explain their peers' decisions included to help their families economically (48\%), peer or friend influence (47\%), and not feeling like a part of the school (32\%). Girls as compared with boys in the sample differed in their beliefs of which reasons lead their peers to dropout: personal reasons ( $81 \%$ vs. $68 \%$ ), academic struggles ( $50 \%$ vs. $58 \%$ ), and not feeling a part of the school (46\% vs. $18 \%)$.

\section{What Are the Problems/Dangers That You Face at School, If Any?}

Most students (51\%) selected "discrimination/racism from other students" as the major problem they faced at school. The next most frequent problem was "violence/drugs/gangs," at $42 \%$. "Lack of English" (34\%) was the third most highly rated problem, which appears to show that even students who rated their English fluency highly in the demographic portion of the survey had academic issues with language. "Peer pressure" was the fourth most common problem (29\%), and the remaining responses were indicated by less than $20 \%$ of the students:

discrimination from adults, lack of academic achievement, lack of support, and low teacher expectations.

\section{What Makes It Hard For Your Peers to Stay in School?}

The most commonly reported theme for this open-ended question was "difficulty in understanding or completing their school work" (22\% or 104 youth responded with an answer of this type). A female student said, "There's just too much work, and you can't understand, and nobody cares about school whether they pass or not.” The next most frequently reported themes 
were "pressure to help their family economically" (68 youth, or 15\%). One young man stated, "Some of my friends have or have tried to drop out due to lack of interest in their school work or because they want to work to support their families." Peer pressure was another prominent theme (50 youth, or 11\%). Another male student reported, "It's their friends that they see having fun and doing what they want.” The next four themes were suggested by 36 to 45 students (8\% to $10 \%)$ : no true interest in school, gang involvement or drugs, misunderstandings at home, and discrimination by peers and teachers. Though less frequent, the response "becoming pregnant" also occurred (25 youth or 6\%).

\section{What Kind of Services and/or Classes Would Help Prevent Students From Dropping Out of School?}

The most often reported suggestion was academic support in the form of tutoring, mentoring, and after-school programs (indicated by 113 students or 28\%). Students suggested: “A tutor who can assist them at their convenience this way they wont have an excuse not to study" and "Activities or clubs that are fun and would get students involved and interested in their education.” The next most common was students' suggestion to have improved ESL classes and more Spanishspeaking staff (indicated by 63 students, or 16\%). Another 60 students (16\%) reported that they thought improved communication with teachers/faculty would improve their peers' likelihood to stay in school. One young lady reported, "Teachers need to learn to at least listen to them." Motivation and support from teachers or staff was chosen by 49 students (13\%), and having classes that students enjoy more or potentially lead to a profession was chosen by 46 (12\%). About 9\% of the students (33) indicated having more information about the consequences of dropping out, and 23 students (6\%) reported that "other” factors such as involvement in extracurricular school activities or increased parent-teacher communication would help reduce their peers' dropout intentions. Interestingly, a total of 377 students (75\%) mentioned areas directly related to the quality of their educational and interpersonal experience (i.e., tutoring, Spanish-speaking teacher, teacher support/motivation, relevant classes).

\section{How Important Would It Be to Have Certain Services/Classes Offered in Order to Prevent Students From Dropping Out of School?}

The large majority of youth in the sample (80\% of youth) reported that they felt dropout prevention programs would be very important, whereas only $1.5 \%$ felt such services would not be important, and 18\% felt they would be somewhat important.

\section{What Kind of Services and/or Classes Would You Like to Be Offered in Order to Help You as a Student?}

Fifty-two percent of the youth in the study selected tutoring as the key to helping them succeed as a student. In addition, 44\% indicated the importance of after-school programs, followed by motivation/support programs (40\%) and help with English (38\%). 


\section{What Do You Think Could Be Done to Prevent Youth From Dropping Out of School?}

When asked an open-ended question about what should be done to address the Latino dropout problem, 143 students (39\%) indicated that the schools should provide more support (e.g., encouragement from teachers, more Spanish speaking teachers, time to speak with counselors). Support seemed to span both academic and personal realms, with comments such as "make them feel more welcome and part of school" and "having people that can help the students so that they can solve their problems." Youth shared things such as "Need lots more support from parents and teachers" and "Give them a lot of support motivating them to keep going forward." Sixtynine students (18\%) said that after-school programs or special tutoring services should be provided. For example, one youth shared, "Help them with their classes by having a special kind of program or class that could help them or advice them what good opportunities could they have done without dropping out of school.” Fifty-three students (14\%) suggested someone should help those peers with their goals, and 43 students (11\%) reported that their peers needed increased parental involvement (e.g., better communication with school staff, parental support in academics). Students reported, "Talk with the parents and students about problems and make a plan," "More support from mother and father," "Help them when they need the help, and start talking to their parents” (implying that school staff could do more to connect with Latino parents).

\section{Discussion}

The goal of this study was to investigate Latino youth's perceptions of why their peers drop out, as well as what they think could be done to encourage their peers to stay in school. Five reasons that this sample of Latino youth gave for why their peers dropped out included (in order of importance) the following: personal reasons (pregnancy or problems at home), difficulty of school work, wanting to work, supporting one's family economically by working, and peer pressure. In the following we comment on each.

First, the importance of family relationships and connections with others was an underlying theme in the responses of these youth. Approximately $75 \%$ of the students ( $81 \%$ females) on the multiple select question marked personal reasons (with examples of pregnancy and problems at home) as a factor causing their peers to drop out. From the open response qualitative data we learned that these personal reasons included pregnancy, misunderstandings at home, no parental support, family immigration/documentation issues, and parental job loss. These family factors when added together accounted for more than 35\% of the qualitative responses. Of these, Latinas mentioned pregnancy most often, with phrases such as “a lot of times they get pregnant." Others have also identified teen pregnancy as a recurring problem among this ethnic group, which further confirms our findings (Hamilton et al., 2007; Ventura et al., 2007).

Insights from qualitative responses clearly demonstrated that youth felt that parent involvement was an important strategy to help their peers stay in school. These findings paralleled work of 
many researchers who have found that parent involvement may be the most important factor predicting academic achievement among Latino youth (Alfaro et al., 2006; GonzalezDeHass et al., 2005; Zuniga, 2004). Youth suggested that parents are a big part of the solution with comments such as "You need to educate their families and tell their family that if their children graduate they would have a better future" and "Have meeting with their parents and talk to them about the importance of attending to school." Clearly more efforts are needed to bridge language and cultural barriers to make parental involvement a reality for these youth.

While the primary obstacle for school success was seen as personal problems by these youth, the primary solutions they suggested were all related to increased academic and interpersonal support. In collectivistic cultures relational constructs such as simpatía are key to success throughout life and may have particular salience for Latino youth navigating the demands of U.S. public schools. Simpatía is a cultural script that refers to the expectation of high frequencies of positive social interactions and low frequencies of negative social behaviors and is associated with seeking to promote harmony in relationships through being respectful toward others and avoiding conflict (Díaz-Loving \& Draguns, 1999; Triandis, Marín, Lisansky, \& Betancourt, 1984). Being unaware of the presence of this cultural script may produces misunderstandings and problems among Latinos and non-Latinos. For example, Euro-American teachers in middle school may seem to be relatively more cold and aloof compared with elementary school teachers, making the transition into secondary education more challenging from a Latino cultural perspective and decreasing positive institutional bonds that buffer against dropout.

Beyond the cultural differences between the Latino students and EuroAmerican teachers, there may be environmental differences that exacerbate the cultural difficulties. For example, changing of classrooms may not give the Latino student ample opportunity to develop the kind of interpersonal relationship that allows for feelings of support and the confidence to approach teachers with their problems. Additionally, Euro-American youth under the influence of a more individualistic cultural mindset may more frequently ask for help when they need it, while Latino youth may see this action as a lack of respect. More research is needed to uncover how complex cultural scripts interact with the environment to influence Latino youth behaviors.

Still, survey results supported the conclusion that youth highly value teachers who they felt really cared about them and would "go the extra mile" for them. The word "support" was used repeatedly in the open-ended comments, often to bridge academic and personal concerns. The suggestions emerging from study participants had a common theme of desiring more connection. Particularly for individuals from collective cultural traditions, relationships that build connection and social capital can increase attachment to school and make dropout less likely (Brewster \& Bowen, 2004). Relationships with adults (parents, counselors, and teachers) are protective assets that can lessen the impact of any "risk" related variables for students.

Students also indicated that teachers, counselors, and other school staff could be leaders in helping them feel welcome and a part of the school, especially in light of the responses about 
some discrimination from student peers. We suggest that future efforts include support to help ESL teachers (and other teachers, counselors, staff, and resource persons working with Latino youth) learn to connect effectively with their students. Teachers who can demonstrate personalismo or highly personable relations with these youth and their parents (Lessard et al., 2008) are needed. Because many teachers often indicate that time and work pressures make visiting with youth and families very difficult, we would suggest that teachers or counselors be granted more time for relationship-building activities (e.g., home visits, phone calls, field trips). This is particularly important for staff that works with high-risk youth. A school culture that values the contributions of family members and attempts to collaborate with them respectfully has been shown Hispanic Journal of Behavioral Sciences 32(3)to have an impact on increasing positive outcomes and reducing risk (DotsonBlake et al., 2009).

Students indicated the need for more Spanish-speaking staff, counselors, and teachers, as well as improved communication between youth and school staff. This suggestion compliments the recommendations of Excelencia in Education, a public policy institute based in Washington, D.C., that published a report titled "What Works for Latino Students" (Santiago \& Brown, 2004). This report outlines two ways in which communication might be improved between Latino youth, their parents, and school staff. First, participants expressed a need for teachers and staff with whom they can identify, those who come from a similar culture to them, and those who understand what they are experiencing. They indicated that this would help them feel more comfortable in their school and better understood by those in their school. Similarly, students reported that they needed more support and help understand (a) what options were available to them beyond high school, (b) information on how to get to college, and (c) details about scholarships. These are roles often fulfilled by school counselors, most effectively by focusing on students' assets and not their perceived deficits (Robledo Montecel, Cortez, \& Cortez, 2004).

The differences across these relational contexts can be confusing for an adolescent who may also be working through stages of adjustment to a new cultural environment and identity development (Thorn \& Contreras, 2005). Structures that help engage Latinos in their school relationships (e.g., opportunities for support from teachers, collaborations with peers, interactions with counselors or ESL staff) have been shown to increase achievement (Conchas, 2001). Phrased another way, dropout can be conceptualized as a school's failure to "hold” the student rather than a student's failure to persist (Robledo Montecel et al., 2004). To adjust for this problem schools may have to go beyond the standard ESL instructors that only address language proficiency and provide teachers with professional training that moves them toward a better understanding of school and relationships from the Latino student's perspective.

Second, students saw academic challenges as an important factor for school dropout. These findings are consistent with those of other large-scale studies of dropout, which generally place academic challenges as a leading factor (Bridgeland et al., 2004; Hernandez \& Nesman, 2004; Perreira et al., 2006). However, much of the historical perspective on Latino dropout has come from the established population areas as opposed to the emerging population areas. An open- 
ended question revealed that many of these students struggled with English, making all of their academics difficult (Perreira et al., 2006). One student commented, "Because have trouble with English can't understand ... the teachers go to[o] fast.” The relationship among years spent in the United States, available support services for learners of English, and opportunities for inclusion in the English-speaking student community are particularly important for the recent arrival states.

The third and fourth reasons suggested that work was related to student dropout. A prominent body of research has assessed the role of employment in student dropout decisions (Bridgeland et al., 2004; Dagenais et al., 2007). Many students decide not to study in order to work to make money for their family or themselves or because they see no future economic benefit of staying in school. Numerous students shared similar comments: "Us Hispanics we drop-off [sic] because are parents are not getting pay too much, they need to pay bills, we need to make money to help are families." Many of these students felt a continuous pull to join the labor force to help their families. Although punitive measures are by definition oppressive and often have unintended consequences, drop out because of early employment could be improved by legislation prohibiting employment earlier than 18 years during school days and sensible enforcement methods to help employers choose to comply with such legislation (Dagenais et al., 2007). However, students may still feel compelled to help their families and will find ways around such legislation. A better strategy may be for counselors and teachers to help students and their families create a vision for the future by seeing that completing high school is a much more effective way for students to help their families climb out of poverty.

Finally, students in this study commented that their peer's decisions to drop out of school were strongly influenced by the friends of these individuals. Similar to research elsewhere associating negative peer relationships with high school dropout problems (Battin-Pearson et al., 2000; Farmer et al., 2003; Lessard et al., 2008), students suggested, "Why go [to school] when your other friends are skipping." One of the toughest aspects to deal with among Latino boys is peer pressure that makes it "not cool to be considered smart." This often results in boys keeping each other down and often competing to distract their peers and teachers. Other researchers have found that because of the segregated nature of schools, minority youth find their choices of peer groups to be restricted (Steinberg, Darling, \& Fletcher, 1995). For example, Asian American youngsters reported the highest level of peer support for academic achievement but the lowest levels of parental involvement in school-related activities. In contrast, African American parents score among the highest in regard to parental involvement in their child's school, but African American youth find it difficult to gain membership into the "brains" peer group. Therefore, the negative effects of a lack of parental involvement for Asian American students was offset by the homogenizing influence of their peer group, and for African American students, the positive benefits of supportive parents was offset by a lack of support from their peer network. Thus, at Bronfenbrenner's (1979) mesosystem level (intersection of the family and peer microsystems), the macrosystemic influence of a culture that promotes segregation was a moderating factor. 
Given these findings, prevention programs might consider the importance of setting up numerous role models, creating images of success that result from academic study, cultivating true friendships among students, and encouraging opportunities for youth to support one another as they participate in the positive activities they enjoy.

A study conducted by the North Carolina Society of Hispanic Professionals with a similar group of youth in 2004 found that discrimination by peers was the most commonly reported problem Latino youth noted experiencing in school (Valencia \& Johnson, 2006). Previous studies have suggested strategies to improve cultural flexibility (reducing discrimination), which include introducing culturally relevant topics in courses at school, helping bridge the differences among peer groups, integrated sporting and social activities, and creating a more culturally supportive environment (e.g., safety, teacher sensitivity to all students, higher educational expectations for all students; Bridgeland et al., 2004; Martinez et al., 2004). There is a role for counselors, teachers, and administrators in these suggestions.

In conclusion, this study provides important information about what students think will help their peers stay in school. The top three suggestions from youth in this study included (a) academic and personal support in the form of tutoring, mentoring, after-school programs; (b) improved ESL classes; and (c) more Spanish-speaking staff/teachers. A modest number of programs exist that target Latino youth via tutoring, mentoring, or after-school programs. However, more support is needed for groups doing this kind of work, such as Blue Ribbon Mentor Advocates, AIM, Upward Bound, Gear Up, ALAS, ENLACE, and AVID clubs (Gándara et al., 1998; Robledo Montecel et al., 2004). Frum (2007) has posited that programs are needed that "create a seamless K-16 approach that addresses high drop-out rates” among Latino youth while helping youth aspire for a postsecondary education (p. 100). Increased support and evaluation of these and other research based programs for youth would improve the Latino dropout phenomenon in new arrival states and in other parts of the United States.

The context of new arrival states is challenging for several reasons. Respondents in this study were eager for improved connections to their teachers, counselors, and peers-connections that may not have been occurring in part because of a lag in structures and resources to meet the needs of this growing population. The students were interested in support for their personal concerns and academic resources to assist them in improving their academic progress. Students also expressed concern for the situation of their families, most often caused by economic pressures. Fiscal problems may have disproportionate impact on new immigrants, so the current economic climate does pose challenges. Schools are also less able to provide resources in difficult financial times and may contemplate elimination of support programs (Capps, 2009). However, finding ways to connect with students does not need to be expensive. If dropout is an expression of disengagement with a system, these students seemed hopeful that engagement with their schools could still happen. As prominent scholars of the dropout crisis, Velez and Saenz (2001) have commented, "improving educational opportunities for Latino youth will require significant cooperation among different key players including students, families, teachers, 
administrators, policymakers, community and business leaders, researchers, and governmental officials” (p. 465).

\section{Authors' Note}

This article was developed as a collaboration by members of the North Carolina Society of Hispanic Professionals-a statewide nonprofit organization-whose only mission is to promote education among Hispanic youth in North Carolina.

\section{Acknowledgment}

We appreciate the help provided by members of the North Carolina Society of Hispanic Professionals, including Tara Ashton, Carole Klein, Catherine Stalberg, Whitney Woodyard, Marco Zárate, and Susan Zárate, who gave inputs and took part in discussion meetings held for this study.

\section{Declaration of Conflicting Interests}

The author(s) declared no conflicts of interest with respect to the authorship and/or publication of this.

\section{Funding}

The author(s) received no financial support for the research and/or authorship of this article.

\section{References}

Alfaro, E., Umaña-Taylor, A., \& Bámaca, M. (2006). The influence of academic support on Latino adolescents’ academic motivation. Family Relations, 55, 279-291.

Anderson, K. V. (2004). Educating America’s Latino youth: A critical review of drop-out prevention literature. Dissertation Abstracts International: Section B: Sciences and Engineering, 65, 3141.

Aspiazu, G. G., Bauer, S. C., \& Spillett, M. (1998). Improving the academic performance of Hispanic youth: A community education model. Bilingual Research Journal, 22, 103-123.

Bámaca, M. Y., \& Umaña-Taylor, A. J. (2006). An ecological approach to understanding resistance to peer pressure among Mexican-origin adolescents. Journal of Youth \& Adolescence, 35, 631-645.

Battin-Pearson, S., Newcomb, M. D., Abbott, R. D., Hill, K. G., Catalano, R. F., \& Hawkins, J. D. (2000). Predictors of early high school dropout: A test of five theories. Journal of Educational Psychology, 92, 568-582. 
Brewster, A. B., \& Bowen, G. L. (2004). Teacher support and the school engagement of Latino middle and high school students at risk of school failure. Child and Adolescent Social Work Journal, 21, 47-67.

Bridgeland, J. M., Dilulio, J. J., \& Burke Morison, K. (2006). The silent epidemic: Perspectives of high school dropouts. Washington, DC: Civic Enterprise, LLC.

Bronfenbrenner, U. (1979). The ecology of human development: Experiments by nature and design. Cambridge, MA: Harvard University Press.

Capps, R. (2009). Immigrant youth issues in the US. Presentation for national webcast by the National Governor's Association. Retrieved from

http://media.nga.org/2009/090603WebcastImmigrants.wmv

Capps, R., Fix, M., Ost, J., Reardon-Anderson, J., \& Passel, J. (2004). The health and well-being of young children of immigrants. Washington, DC: Urban Institute.

Ceballo, R. (2004). From barrios to Yale: The role of parenting strategies in Latino families. Hispanic Journal of Behavioral Sciences, 26, 171-186.

Clemente, R., \& Collison, B. (2000). The relationships among counselors, ESL teachers, and students. Professional School Counseling, 3, 339-348.

Conchas, G. (2001). Structuring failure and success: Understanding the variability in Latino school engagement. Harvard Educational Review, 71, 475-504.

Constantine, M. G., Kindaichi, M. M., \& Miville, M. L. (2007). Factors influencing the educational and vocational transitions of Black and Latino high school students. Professional School Counseling, 10, 261-265.

Cox, R., Shreffler, K., Schwerdtfeger, K., \& Merten, M. (2010). /Pathways to school success study/ (Technical Report to the Oklahoma City Public School System). Stillwater, OK:

Oklahoma State University.

Dagenais, M., Montmarquette, C., \& Viennot-Briot, N. (2007). Dropout, school performance, and working while in school. Review of Economics and Statistics, 89, 752-760.

Delgado-Gaitan, C. (1992). School matters in the Mexican-American home: Socializing children to education. American Educational Research Journal, 29, 495-513.

Delgado-Gaitan, C. (1994). Socializing young children in Mexican American families: An intergenerational perspective. In P. M. Greenfield \& R. R. Cocking (Eds.), Cross-cultural roots of minority child development (pp. 55-86). Hillsdale, NJ: Erlbaum. 
Díaz-Loving, R., \& Draguns, J. G. (1999). Culture, meaning, and personality in Mexico and in the United States. In Y. T. Lee, C. R. McCauley, \& J. G. Draguns (Eds.), Personality and person perception across cultures (pp. 103-126). Mahwah, NJ: Erlbaum.

Dinan, K. A. (2005). Federal policies restrict immigrant children's access to key public benefits: A children in low-income immigrant families policy brief. New York, NY: National Center for Children in Poverty.

Dotson-Blake, K. P., Foster, V. A., \& Gressard, C. F. (2009). Ending the silence of the Mexican immigrant voice in public education: Creating culturally inclusive familyschool-community partnerships. Professional School Counseling, 12, 230-239.

Eaton, D. K., Kann, L., Kinchen, S., Shanklin, S., Rossm J., Hawkins, J., . . W Wechsler, H. (2008). Youth Risk Behavior Surveillance: United States, 2007. Morbidity and Mortality Weekly Report, 57(SS-4), 1-131.

Ellenbogen, S., \& Chamberland, C. (1997). The peer relations of dropouts: A comparative study of at-risk and not at-risk youths. Journal of Adolescence, 20, 355-67.

Falbo, T. (1996, August). Latino youth and high school graduation. Invited address at the annual meeting of the American Psychological Association, Toronto, Ontario, Canada.

Farmer, T. W., Estell, D. B., Leung, M., Trott, H., Bishop, J., \& Cairns, B. D. (2003). Individual characteristics, early adolescent peer affiliations, and school dropout: An examination of aggressive and popular group types. Journal of School Psychology, 41, 217-232.

Frum, J. (2007). Postsecondary educational access for undocumented students: Opportunities and constraints. American Academic, 3, 81-108.

Gándara, P., Larson, K. A., Mehan, H., \& Rumberger, R. W. (1998). Capturing Latino students in the academic pipeline. Berkeley, CA: Chicano/Latino Policy Project.

Glennie, E. J., \& Stearns, E. (2002). Why Hispanic students drop out of high school early: Data from North Carolina [Policy Brief]. Durham, NC: Center for Child and Family Policy, Duke University.

Gonzalez-DeHass, A., Willems, P., \& Holbein, M. (2005). Examining the relationship between parental involvement and student motivation. Educational Psychology Review, 17, 99-123.

Gottlob, B. J. (2007). The high cost of low graduation rates in North Carolina. Indianapolis, IN: Milton and Rose D. Friedman Foundation and Parents for Educational Freedom in North Carolina. 
Hamilton, B. E., Martin, J. A., \& Ventura, S. J. (2007). Births: Preliminary data for 2006 (National Vital Statistics Reports, Vol. 56). Hyattsville, MD: National Center for Health Statistics.

Hernandez, M., \& Nesman, T. (2004). Issues and strategies for studying Latino student dropout at the local level. Journal of Child and Family Studies, 13, 453-468.

Hess, R. S. (2000). Dropping out among Mexican American youth: Reviewing the literature through an ecological perspective. Journal of Education for Students Placed at Risk, 5, 267-289.

Kasarda, J., \& Johnson, J. (2006). The economic impact of the Hispanic population on the state of North Carolina. Chapel Hill, NC: Frank Hawkins Kenan Institute of Private Enterprise.

Katz, S. R. (1999). Teaching in tensions: Latino immigrant youth, their teachers, and the structures of schooling. Teacher College Record, 100, 809-841.

Lagerwey, M. D., \& Phillips, E. (2003). Voices from the pipeline: High school completion among rural Latinos. Journal of Cultural Diversity, 10, $42-49$.

LeCompte, M. D., \& Priessle, J. (1993). Ethnography and qualitative design in educational research. San Diego, CA: Academic Press.

Lessard, A., Butler-Kisber, L., Fortin, L., Marcotte, D., Potvin, P., \& Royer, E. (2008). Shades of disengagement: High school dropouts speak out. Social Psychology of Education, 11, 25-42.

Lopez, L. C., \& Sanchez, V. V. (2000). Immigrant and native-born Mexican-American parents' involvement in a public school: A preliminary analysis. Psychological Reports, 86, 521-525.

Marotta, S. A., \& Garcia, J. G. (2003). Latinos in the United States in 2000. Hispanic Journal of Behavioral Sciences, 25, 13-34.

Martinez, C. R., DeGarmo, D. S., \& Eddy, J. M. (2004). Promoting academic success among Latino youths. Hispanic Journal of Behavioral Sciences, 26, 128-151.

Muñoz, C. B. (2009). A dream deferred: Undocumented students at CUNY. Radical Teacher, 84, 8-17. Retrieved from http://rt.press.illinois.edu/84/munoz.html

North Carolina Department of Public Instruction. (2009). North Carolina four-year cohort graduation rates. Raleigh, NC: Author.

Patton, M. Q. (1990). Qualitative Evaluation and Research Methods (2nd ed.). Newbury Park, CA: Sage Publications, Inc.

Perreira, K. M., Harris, K. M., \& Lee, D. (2006). Making it in America: High school completion by immigrant and native youth. Demography, 43, 511-536. 
Pew Hispanic Center. (2004). Pew Hispanic Center/Kaiser Family Foundation 2004 National Survey of Latinos. Retrieved from http://pewhispanic.org/reports/report .php?ReportID=33

Plunkett, S. W., \& Bámaca-Gómez, M. Y. (2003). The relationship between parenting and adolescent academic outcomes in Mexican-origin immigrant families. Hispanic Journal of Behavioral Sciences, 25, 222-239.

Portes, A., \& MacLeod, D. (1996). Educational progress of children of immigrants: The roles of class, ethnicity, and school content. Sociology of Education, 69, 255-275.

Ramirez, A. Y. F. (2003). Dismay and disappointment: Parental involvement of Latino immigrant parents. Urban Review, 35, 93-110.

Robledo Montecel, M., Cortez, J. D., \& Cortez, A. (2004). Dropout-prevention programs: Right intent, wrong focus, and some suggestions on where to go from here. Education and Urban Society, 36, 69-188.

Rouse, C.E. (2005). The Labor Market Consequences of an Inadequate Education. Paper Presented at the Equity Symposium on “The Social Costs of Inadequate Education” at Teachers' College, Columbia University. Princeton, NJ: Princeton University and NBER. Retrieved July 2009 from:http://www.tc.edu.

Rumberger, R. W. (1995). Dropping out of middle school: A multilevel analysis of students and schools. American Educational Research Journal, 32, 583-625.

Rumberger, R. W., Larson, K., Ream, R., \& Palardy, G. (1999). The educational consequences of mobility for California students and schools (Report prepared for policy analysis for California Education, PACE). Berkeley, CA: University of California, Berkeley, and Stanford University.

Rumberger, R. W., \& Thomas, S. (2000). The distribution of dropout and turnover rates among urban and suburban high schools. Sociology of Education, 73, 39-67.

Santiago, D. A., \& Brown, S. E. (2004). What works for Latino students. Retrieved from http://www.edexcelencia.org/research/what_works.asp

Schmid, C. L. (2001). Educational achievement, language-minority students, and the new second generation. Sociology of Education, 74(Suppl.), 71-87.

Smith-Adcock, S., Daniels, M. H., Lee, S. M., Villalba, J. A., \& Indelicato, N. A. (2006).

Culturally responsive school counseling for Hispanic/Latino students and families: The need for bilingual school counselors. Professional School Counseling, 10, 92-101.

Stamps, K., \& Bohon, S. A. (2006). Educational attainment in new and established Latino metropolitan destinations. Social Science Quarterly, 87, 1225-1240. 
Steinberg, A., Johnson, C., \& Pennington, H. (2006). Addressing America’s dropout challenge: State efforts to boost graduation rates require federal support. Washington, DC: Center for American Progress.

Steinberg, L., Darling, N. E., \& Fletcher, A. C. (1995). Authoritative parenting and adolescent adjustment: An ecological journey. In P. Moen \& G. H. Elder Jr. (Eds.), Examining lives in context: Perspectives on the ecology of human development (pp. 423-466). Washington, DC: American Psychological Association.

Stone, S., \& Han, M. (2005). Perceived school environments, perceived discrimination, and school performance among children of Mexican immigrants. Children and Youth Services Review, 27, 51-66.

Thorn, A. R., \& Contreras, S. (2005). Counseling Latino immigrants in middle school. Professional School Counseling, 9, 167-170.

Triandis, H. C., Marín, G., Lisansky, J., \& Betancourt, H. (1984). Simpatía as a cultural script of Hispanics. Journal of Personality and Social Psychology, 47, 1363-1375.

U.S. Census Bureau. (2008). Current Population Survey, 2007. Washington, DC: Government Printing Office.

Valencia, E. Y., \& Johnson, V. (2006). Latino Students in North Carolina: Acculturation, perceptions of school environment, and academic aspirations. Hispanic Journal of Behavioral Sciences, 28, 350-367.

Velez, W., \& Saenz, R. (2001). Toward a comprehensive model of the school leaving process among Latinos. School Psychology Quarterly, 16, 462-475.

Ventura, S. J., Abma, J. C., Mosher, W. D., \& Henshaw, S. K. (2007). Estimated pregnancy rates by outcome for the United States, 1990-2004 (National Vital Statistics Reports, Vol. 56). Hyattsville, MD: National Center for Health Statistics.

Villalba, J. A., Brunelli, M., Lewis, L., \& Orfanedes, D. (2007). Experiences of Latino children attending rural elementary schools in the southeastern U.S.: Perspectives from Latino parents in burgeoning Latino communities. Professional School Counseling, 10, 506-509.

Villenas, S. (2002). Reinventing education in new Latino communities: Pedagogies of change and continuity in North Carolina. In S. Wortham, E. Murillo, \&

E. Hamann (Eds.), Education in the new Latino diaspora: Policy and the politics of identity (pp. 17-35). Westport, CT: Greenwood. 
Wall, J. A., Power, T. G., \& Arbona, C. (1993). Susceptibility to antisocial peer pressure and its relation to acculturation in Mexican-origin adolescents. Journal of Adolescent Research, 8, 403418.

Western Interstate Commission for Higher Education. (2003). Knocking at the college door: Projections of high school graduates by state, income, and race/ethnicity.Boulder, CO: Author and College Board.

Zota, S. (2009) Unauthorized immigrants' access to higher education: Fifty states, different directions. Popular Government, 74, 46-54.

Zuniga, K. Z. (2004). The influence of individual characteristics and parenting behaviors on adolescent academic performance (Unpublished doctoral dissertation). Iowa State University, Ames.

Bios

Andrew O. Behnke, PhD, is an assistant professor of human development at North Carolina State University, Raleigh. He received his PhD from Purdue University. He developed the “Juntos” dropout prevention program along with Cintia Aguilar. He conducts applied research and outreach on academic achievement among Latino youth, parent involvement in academics, stress and parenting, and Latino fatherhood. His life mission is bringing better attention to those factors that help immigrant Latino families succeed and thrive in the United States. He enjoys creating imaginary adventures with his three boys and his princess of a daughter.

Laura M. Gonzalez, PhD, is an assistant professor of counseling and educational development at University of North Carolina-Greensboro. She received her PhD from North Carolina State University. Her research agenda includes using variables from social cognitive career theory (such as self-efficacy beliefs, outcome expectations, environmental influences, and learning experiences) to understand Latino adolescents’ college planning and choices. She is the coordinator for the College Counseling and Student Development track, and thus is interested in both improving the postsecondary access and success of Latino students and preparing the next generation of student services professionals who will work with them. Her three Panamanian American children will be ready for college in 2025.

Ronald B. Cox Jr., PhD, is an assistant professor of human development and state extension specialist at Oklahoma State University, Stillwater. He received his PhD from Michigan State University in family and child ecology. He is also the director for the Oklahoma State University Center for Family Risk and Resilience. His research involves contextual factors as risk regulators in the development high-risk behaviors in adolescents with a focus on Latino youth. He has conducted research on parenting, social economic status, school climate, dropout, the work 
family environment, discrimination, and acculturation as it pertains to adolescent risk and resilience.

His most recent projects include studies investigating the development of social competence among Mexican youth, substance abuse among adolescents in Venezuela, and school dropout among Latino youth in Oklahoma. 